University of Nebraska - Lincoln

DigitalCommons@University of Nebraska - Lincoln

Agronomy \& Horticulture -- Faculty Publications

Agronomy and Horticulture Department

1969

Systems Analysis of Natural Resources and Crop Production

Marion Clawson

Washington, D. C.

Follow this and additional works at: https://digitalcommons.unl.edu/agronomyfacpub

Part of the Plant Sciences Commons

Clawson, Marion, "Systems Analysis of Natural Resources and Crop Production" (1969). Agronomy \& Horticulture -- Faculty Publications. 189.

https://digitalcommons.unl.edu/agronomyfacpub/189

This Article is brought to you for free and open access by the Agronomy and Horticulture Department at DigitalCommons@University of Nebraska - Lincoln. It has been accepted for inclusion in Agronomy \& Horticulture -Faculty Publications by an authorized administrator of DigitalCommons@University of Nebraska - Lincoln. 
Published in Physiological Aspects of Crop Yield: Proceedings of a symposium sponsored by the University of Nebraska, the American Society of Agronomy, and the Crop Science Society of America, and held at the University of Nebraska, Lincoln, Nebr., January 20-24, 1969. Edited by Jerry D. Eastin, F. A. Haskins, C. Y. Sullivan, C. H. M. Van Bavel, and Richard C. Dinauer (Madison, Wisconsin: American Society of Agronomy \& Crop Science Society of America, 1969). Copyright (C) 1969 American Society of Agronomy \& Crop Science Society of America. Used by permission. 


\section{Systems Analysis of Natural Resources and Crop Production}

\section{MARION CLAWSON}

Resources for the Future

Washington, D. C.

Human history is a seamless web; every event has its antecedents, its contemporaries, and its consequences. Each event arises out of the past, each is associated with other events at the time, and each leads to new events, in an endless chain. Indeed, there is difficulty in isolating any single event; when did it begin, what are its boundaries, when did it end? These are some of the problems of the social scientist generally, and of the historian in particular.

Nature is equally a seamless web. Every natural process or event has its cause or antecedent, each takes place within a complex matrix or environment, and each leaves its consequences, out of which in time flow other events or processes. As with human history, it is sometimes difficult to define an event or a process in nature--to mark its beginning, its boundaries, its ending. At the least, it is necessary to define and to limit both events and processes, and to put each in a setting--a chemical reaction at a specified temperature and pressure, in specified concentrations, with stated degrees of impurities present, for instance. Man has established fields of knowledge or professions, such as chemistry, agronomy, genetics, and the like; but nature knows no such categories. Increasingly, we find that the really important and difficult problems lie at the crossroads of two or more of our selfestablished professions, rarely squarely within any one field of knowledge.

\section{REQUIREMENTS OF CROP PRODUCTION}

At the risk of gilding the lily, let me point out that this concept of the seamless web applies to crop production also. The requirements for successful crop production are several: a plant capable of producing a product desired by man, with efficiency; a soil capable of provid- 
ing support to the plant and of holding at least a minimum of some moisture, preferably with some plant nutrients that it can yield up to the plant; other sources of plant nutrients from mineral deposits in other areas, applied as needed by the crop; enough, but not too much, water, either falling as natural precipitation or applied as irrigation; a reasonable control of plant diseases, insect pests, weeds, and other rivals or inhibitors; and many other factors. Each of these necessary inputs in turn has its antecedents. All of these and other, factors must be present in at least a reasonably favorable degree; the absence or the scarcity of any one may limit the crop severely. You are each vastly more familiar with all this than am I; I am simply refreshing our memories, and supplying a common starting point for further consideration.

Any plant production, whether intended or not, leaves its consequences. It is not enough to produce; the product must be utilized, and this in turn requires many steps and often an elaborate organization. Moreover, the waste must be disposed of. A product is defined as something man wants from the crop growth and production--something directly useful for his needs, or indirectly so (e.g., food for his domestic animals or even game animals and birds). The usefulness of a crop output depends in large part upon the facilities man has constructed to use it (e.g., transportation facilities of all kinds and means of storing and preserving from harvest time until the product is needed).

But waste also results from most plant or crop production. Waste may be simply defined as a material in the wrong place and time. My old botany professor defined weeds as valuable plants growing in the wrong time and place, and waste is analogous. Everything produced (or transformed) by plants must somehow be disposed of, somewhere, some time, in some way. The total volume of all production must show up as wastes in solid, liquid, or gaseous form, except as there is direct recycling of some products in the production processes. This is simply the law of the conservation of matter applied to economic outputs. When looked at in this way, the problems of pollution appear in somewhat differentperspective; all produce, when it has served its primary purpose, becomes waste and pollution in some form.

The animal manures resulting from large scale cattle feeding operations, or from large scale intensive broiler or egg production enterprises, may create a serious waste and pollution problem, given their concentration at one place and point in time. But these materials are also highly valuable plant nutrients, carefully saved and husbanded in an earlier age in our country and highly valued yet in many lands. Anyone who has seen the eagerness with which women and children in some countries scoop up freshly made cow manure, and convert it to a cake for drying and later use as fuel, may wonder how such people would view a modern large scale beef feeding lot. Or the plant nutrients which wash from the soil and create such undesirable growths of algae in nearby ponds are but a part of the valuable additions made to the soil so that it can grow plants. You can surely add many more examples of chemicals or other materials highly valued in one place but a liability elsewhere. Even water falls in this category--the scarcity of the desert leads to one evaluation, the destructiveness of the flood to another. 
Modern man is industrial and urban, more than he is rural and agricultural. In the modern city, everything that comes in--food, fuel, clothing, shelter materials, water, etc.--must somehow be disposed of, by flushing down the river, by burning and discharge to the atmosphere, or by covering up as land fill. Materials management is coming to replace waste disposal, as the best term to describe what is involved. Increasingly, we realize that production, or the placing of a desired good in the hands of the consumer, is not the end of the technological and economic processes involved. Until the waste is somehow disposed of, and preferably to a place and in a condition where it can enter the productive cycle anew, the production-consumption process is not ended.

In my youth, I learned about the hydrologic and the nitrogen cycles-how water was evaporated, transported by clouds, precipitated from them, and how it behaved on the land and in water bodies, and similarly how the nitrogen moved from atmosphere to various forms on earth and in plants and animals, and back again to the air. These particular cycles are still valid, but incomplete as a means of describing production of desired plant and animal materials and of disposing of them as wastes. It is now clear that there are cycles for all basic elements and for their compounds. Many cycles are complex, the paths variable, and the time length may befar beyond human control, or possibly human comprehension. Discoveries in recent decades of substantial deposits of metals or relatively simple metallic compounds on the ocean floor has opened new vistas about this matter of materials cycles. For a long time, we considered iron,copper, lead, tin, and other metals as exhaustible materials, or stock resources, not subject to replacement, while such other materials as wood fiber were considered replaceable or flow resources. But now we know that the so-called stock resources do not disappear, though their cycles may be such that we cannot recapture them readily. The lead we mine from a deposit does not disappear forever, merely because it is discharged into the atmosphere when the gasoline in which it was dissolved is burned.

\section{ASPECTS OF NATURAL RESOURCES}

The quantity and quality of natural resources readily available for use has been the subject of much concern by many people for many centuries; but I think it can reasonably be argued that there has been a rising tide of popular interest in the subject in recent years. In particular, the quality aspects of the problem have had increasing emphasis, with much concern over water and air pollution, over landscape degradation, over natural beauty, and all the rest of it. In one sense, everyone understands what is meant by natural resources, yet I suggest there may indeed be some lack of common understanding of at least some aspects of the term.

In my research, I have found it helpful to use a definition of natural resources which includes four parts: (i) Any quality or characteristic of nature, (ii) which we know how to use, (iii) economically, and (iv) to a desired end. 


\section{A. Qualities of Nature}

In an earlier day, we tended to define natural resources only in terms of tangible assets such as soils, forests, and mineral deposits. We developed intensive and complex ways of measuring such resources, and of describing them. There is a whole language to describe soils, for instance--the old measures, such as A, B, and C horizons, or clay, loam, and sand, and others, to which I was exposed in my youth, are no longer adequate, but they were helpful in their time. Likewise, mineral deposits can be measured in various ways, even estimated prior to underground explorations, and described in terms of concentrations of desired materials, presence of other chemicals, and the like. Or forests can be measured in terms of volume and grade of various tree species, and evaluated in terms of costs of getting out the logs, of sawmill outturn, and the like.

All of these, and associated attributes of these resources are still important, at least under many circumstances. But we are learning that many other attributes of nature may be highly valuable also. Since World War II, for instance, the importance of an amenity climate in which people like to live, and hence a place where skilled workers are likely to be attracted, has become a major natural resource for Florida and the Southwest generally. The capacity of an airshed to absorb gaseous wastes, and to carry them off, has become a major natural resource for many cities. Resources long known, such as uranium, may suddenly acquire a wholly new meaning. Or combinations of forest and water bodies, long known and somehow appreciated, may acquire new importance as recreation resources. Water temperature, not of enough importance to warrant measurement in one era and under one set of conditions, may become critical as one evaluates an area for potential outdoor swimming, for instance. I think that literally any quality or characteristic of nature may become a natural resource, in the human use sense of the term, under some conditions.

\section{B. Technology}

The second part in my definition of natural resources is technology, or the ability to use what we know exists. Until we do know how to use some quality of nature, it is really not a natural resource. Petroleum was not a natural resource to the Plains Indians in 1800; they did not suspect its occurrence in the earth, would have had no means of extracting it if they had known about it, and would not have known what to do with large supplies of it if they had somehow extracted them. Neither, might it be added, was this same petroleum a natural resource to the first white trappers and fur traders in the same area--their knowledge was no better than that of the Indians.

This type of example can be multiplied many times. There are many examples in the case of soils, which you know better than I--soils too heavy to be worked with sources of power and implements then available, or soils lacking in some essential, though perhaps minor, chemi- 
cal element, and many others. A forest species valueless at one period acquires value when we learn how to work its wood; oil shale and tar sands become valuable minerals when we learn how to extract the oil from them. When we learn how to make penicillin, and learn how valuable it is for many purposes, the mold which produces it quickly is recognized as a valuable part of nature, when earlier it had been unknown. I shall not try to list or catalogue examples of the influence of new technology on resource availability; I have not the knowledge to do so, and my point is valid without more examples to illustrate it.

Technology and modern science have been particularly valuable to the economically advanced countries. They have had the economic resources to invest in research and their research has generally, and naturally, been directed toward the solution of their problems. And they have had the capital and the managerial competence to utilize their research results productively. Science and technology have been less helpful, or only dubiously helpful thus far, for the economically less advanced countries. The latter have not been able to conduct much research of their own,imported research is often only partially applicable, and they have been unable fully to exploit such research as there was. Indeed, Gunnar Myrdal (1957) goes so far as to assert that science and technology have worsened the position of the economically less advanced countries; their raw materials are less valuable in international trade simply because science and technology have developed substitutes for them--artificial rubber for natural rubber, plastics for metals, etc.

But, even within a generally economically advanced country such as the United States, technology has greatly shifted the importance of different qualities of nature and of the regions in which each is dominant. Because of thin soils, steep slopes, small fields, and related characteristics the hill and mountain lands from the Appalachians westward are vastly less valuable today because of technology which has shown us how to get more output from the deeper, more nearly level, larger fields in the lowlands and plains; or the value of some sandy soils that respond to fertilizers has risen, while that of other soils has fallen because they lacked this response.

\section{Economics}

Knowing that an attribute or quality of nature exists, and knowing how to make something from it that we want, are not enough in themselves. In addition, the question must always be raised: are the results worth the costs? A great many things can be done which are too costly to be sensible. During one of the gold crises of the last few years, for instance, someone calculated that gold could indeed be made by atomic conversions of lesser metals but that the gold so obtained would cost millions (or billions) of dollars per ounce. Much closer to home, figuratively and geographically for us here today, and much closer to economic practicability: there exist in this country many millions of acres of land which could be farmed, were our need for agricultural commodities great enough and were we willing to accept the low real returns 
that would be involved. Indeed, much land inherently no more productive is farmed in other parts of the world.

There are always vast mineral deposits below a profitably recoverable level; there are extensive forest areas in the world, and even in the United States, where the costs of getting the forest products out, and processed, are greater than the value of the product; there are sources of water which are too costly to utilize profitably; and so on. There has been a lot of publicity about various schemes for moving really large volumes of water from Alaska, or northern Canada, or the Pacific Northwest, to the Southwest of the United States and even into Mexico; likewise, there have been various proposals for large scale desalting of sea water as a basis for commercial agriculture. In each case, a physical material exists and is reasonably well known; the technological process exists and is reasonably well known. But, also in each case, the costs are yet wholly out of line with the results. Or, to take still a different kind of example: alcohol can be made out of wheat [Triticum (aestivum L.) sp.] or other grain, and used to power automobiles, thus relieving the need for some petroleum; but the costs are completely out of line. One does not hear much about this latter example these days, but it was actively discussed some years ago.

To an economist, these questions of value in relation to cost are fundamental. For those commodities traded freely in open markets, the discipline of the market is usually sufficient to sort out the poor from the good possibilities. But natural resources are marked by a considerable degree of public action or of public control over private action; for example, water laws limit or govern water developments. Although elaborate procedures have been built up in some fields of government action, to apply tests of economic rationality, one must agree that these have been somewhat less than perfect in operation. There are many instances in which economic tests have not been applied, and perhaps cannot be so applied. We have not yet evaluated the quality of natural resources very well, nor have we learned very well how to take into account those actions which damage or benefit third parties. And many resource outputs are common goods, available to everyone and hence not easily priced and subject to the discipline of the market.

In spite of all the problems, economists as a professional group, have, I believe, exhibited considerable ability in measuring the worth of resource programs that are not subjected to market evaluations. Indeed, their ability to do so, and the results of their analyses which demonstrate the impracticability of many resource development proposals, have led many economists into situations of tension and criticism.

\section{Goals}

The fourth part of my definition of natural resources is concerned with goals, or with the purposes for which we seek to use resources. Economists have generally assumed that maximization of income was the goal; we have developed many tools for measuring income maxi- 
mization. Generally speaking, all other factors being equal, every individual and every group does indeed prefer more to less--more money income to less, more goods and services to less, more education to less, better housing to poorer, and the like. Although at one time it was sometimes argued that people in lower income groups within this country or in other societies really did not care to maximize their incomes, this idea has been pretty well exploded by now. As T. W. Schultz (1964) has said about illiterate farmers in less developed countries: they may not be able to read, but they can count, and they do prefer more to less. Thus, income maximization as one goal of natural resource use is valid and powerful, and likely to remain so.

The difficulty comes when we assume that income maximization is the only goal of natural resource use. One may value leisure more than income. Can anyone seriously argue that trout fishing is engaged in, as a means of maximizing income? In some societies, cattle are valued as wealth and status symbols, or are clothed with religious values; they are not raised or kept for income maximization. Can any of you seriously argue that your professional activities are dominated by incomemaximization calculations? I presume you prefer a large salary to a small one, but I am also sure that other criteria are often more important than salary. In pursuing a research project, do you carry your research to that precise point where marginal value product exactly equals marginalcost, and no further? I have long argued that my economist friends are poor practitioners of their own methods of analysis, when it comes to their own activities.

It may be argued that the individual who has goals other than maximum economic income does maximize something--social status, personal satisfactions, opinion of his peers or contemporaries, or others. Some ingenious economic analyses have been applied to such problems, and I have contended on other occasions that one can place an economic value on any good or service to which people respond in reasonably predictable fashion (and not necessarily in rational fashion, by your standards and mine). While I think that economic analysis can often be carried much further than it has been, I also think we must never lose sight of the matter of goals or ends, in our resource use, and we must recognize that others may have goals very different from our own.

Perhaps I can illustrate with a couple of current examples. In the last few years, we have heard much about natural beauty, and many people have wakened to the fact that we have often needlessly destroyed much that was beautiful in our environment. I judge that in the future we shall give much more attention to natural beauty than we have in the past. It may be argued this is sound economics--I think it probably is; or it may be argued that a value can be placed on the beauty so preserved or enhanced--I think probably it can be. But the real motivation is not income enhancement, but rather our standards of personal and social behavior, and our goals as to what we should seek from our environment. Or, to take a different illustration, for the past 20 years the world has seen a rather large scale effort by the higher income countries to help the lower income ones develop their economies. It may be argued that this is good business for the richer countries--and 
I think it is; but the major motivation arises from other sources, primarily our moral concern with fellowman.

Perhaps you will not agree with me, but I find this fourfold definition of natural resources a useful one to guide me in my research and in my writing about natural resources. I find the definition useful, as a means of putting many facts and ideas into some kind of order or system. I find it particularly helpful in avoiding consideration of some aspects of natural resources to the exclusion of other equally important aspects.

\section{NATURAL RESOURCES AND THEIR USE AS SYSTEMS}

"System" and "systems analysis" are the "in" terms of our generation; one must talk in such terms, if one is to be up-to-date or pretends to be, and if one is to hold his place in professional circles. While there has been some nonsense spoken and written in the name of systems and systems analysis, yet in fact these are highly useful terms and concepts, and are directly applicable to natural resources.

At its best, the concept of a system provides a means of describing many interrelated factors, and of putting each into some sort of perspective; at its best, systems analysis provides powerful analytical concepts for dealing with these problems of interrelationship. It is now possible to trace or describe an event or a process as part of a larger sequence, to put it in a larger frame of current events and processes, and to trace its consequences further and more accurately. Systems analysis almost requires quantitative measurement and quantitative expression; it is not enough merely to trace sequences, but measurement or approximations as to quantities involved is almost an essential part.

Systems analysis has gotten a tremendous boost from the development of electronic data processing equipment. A relationship may have been known earlier, or at least suspected, but calculations about it were so slow as to be meaningless in solution of any real problems. Computers have changed all this. The computer may be nothing more than a fancy adding machine, but it operates at speeds differing by many orders of magnitude; complex formulae, with many variables, can be applied almost instantly to a large range of data. Moreover, computer formulations can provide explicitly for feedback, and for simultaneous adjustments of several variables, one to another, and for decisions based upon several variables interacting simultaneously.

At the same time, no natural resource system is ever final or complete; each necessarily rests upon antecedent events and processes, each (no matter how comprehensive it may be) operates within a broader framework, and each leaves its consequences for later events and processes. One can consider a system of great complexity. Some of my friends have described to me their system models of salmon fishing for instance, with formulae including hundreds of terms or variables, that they can project ahead for scores of years under alternative assumptions, as to key variables. Nevertheless, no system, however complex, can include literally all variables and all processes--nor even 
all that we know, or think we know about, much less those about which we do not know or suspect.

It is generally recognized that no system analysis can be any stronger than the data and the formulae fed into it. The computer only follows instructions, although these may be quite complex. If we have to guess as to some relationship or as to some fact, then the final result is affected to some degree by that guess. If we keep this clearly in mind, efforts to apply systems analysis to specific problems may help us develop better understanding and better data, and this may be a real accomplishment.

We used to describe relationships in natural resources as competitive, complementary, symbiotic, parasitic, etc. These are still useful terms and ideas, I think. But each can now be given mathematical expression and quantitative content, in a system approach. At one extreme, every increase in one variable may be accompanied by a proportionate decrease in another; at the opposite extreme, every increase in one may be accompanied by a proportionate increase in the second; and all sorts of more complicated intermediate relationships exist. In one sense, every natural resource process is a "zero sum" game, in the language of the systems' analysts, since all matter and all energy are merely transformed, not created nor lost in any absolute sense. In more human terms, many natural resource processes are far from zero sum games, since the gains far exceed the costs and the losses. A crop of wheat is merely transformed energy and transformed chemicals, based upon sunlight, soil nutrients, gases from the air, and water; but the wheat is directly useful for human welfare, while the chemicals and the energy were not. But natural resource processes are not invariably gains; it is wholly conceivable that man is worse off as a result of some resource program. Even more commonly, some men are better off, while others are worse off.

A systems approach may be applied to each of the four parts of our definition of natural resources. You know far better than I how various attributes of nature form a system--how chemicals in the soil, microbiology of the soil, water, and other elements interact; or how the various kinds of vegetation within a forest interact; or how vegetation, soil, water, and human actions may interact to accelerate soil erosion; and many others. One kind of technology often interacts with another; a process may depend upon new metallurgy, or a gain in one field may stimulate development in another; economic demands of ten provide the incentive to technology, or lead to new appraisals of resource characteristics, or these in turn open up new economic possibilities; changing goals and ideals may lead to new resources demands and uses; and so on, the various attributes of natural resources reacting with each other in complex systems.

Every natural resource system use or analysis requires management, or conscious decision making, at various stages. The computer must be programmed; the crop will not grow without decisions at various stages. Though one process or event flows from others, and in turn leads to others, yet the sequences are not invariable nor wholly automatic. Choices not o nly can be made--they must be made at various intervals, and usually they cannot be avoided. Management, as a con- 
scious human activity, can and must enter. It is true that "natural" processes would proceed, were man to vanish from the earth; but natural resource processes from which man hopes to benefit must have his participation. Here is where his understanding of the qualities of nature, his technology, his economics, his goals enter into the whole process; within very wide limits, he can guide the natural processes to his own ends. He is constrained by the past, and his current actions will in turn constrain his descendants, but choices are both possible and necessary.

\section{SOME EXAMPLES}

This discussion of systems analysis for natural resource problems may be illustrated by a brief description of a few examples. Those which follow may not be the most important or best examples, but they are illustrative, and they have the merit (for me) of being cases about which I am at least moderately informed.

\section{A. Water Quality}

The hydrologic cycle, as noted previously, is a natural resource system long recognized as such. Water moves in the air, on the surface of the land, and within the soil and subsoil, in a complex cycle whose exact nature varies from place to place. Man can intervene in the cycle at various points--perhaps by weather modification, surely in affecting speed and relative volume of runoff, obviously in storage behind dams or in pumping from ground water, and in other ways. Until rather recently, the primary emphasis has been upon quantities of water at various stages in the hydrologic cycle, and upon how man might influence those quantities.

But water quality is also readily subject to systems analysis, as my colleagues Kneese and Bower (1968) have shown. Wastes are of many kinds, as we have noted; all life involves wastes, which must be disposed of or removed in some way. Water, particularly running water, is often a prime vehicle for waste disposal. Some persons, firms, or groups gain by use of a given water body for waste disposal by having their wastes carried away. But other persons, firms, or groups may lose as a result of these actions if they had counted on use of this water in a relatively unpolluted condition.

How may the gains be maximized and the losses minimized? A host of possibilities exist, at least in some circumstances. Sometimes the production (or consumption) processes which produced the wastes may be modified to produce less; sometimes the waste materials may be recovered and used productively. Waste discharges may be reduced by various forms of treatment, or may be timed to utilize flood or other peak stream flows. Or water supply conditions may be altered, to provide greater flows at otherwise low flow periods. The water polluters may be given financial incentive to take one or more of these actions; incentives in the form of pollution charges geared to the amount and 
kind of pollutants discharged to the streams. Or the polluters may be restrained from discharging wastes into water bodies by water quality standards, laws, regulations, and other public sanctions.

In this example, all four aspects of my definition of natural resources are involved. The qualities of nature include the chemical, physical, and biologic nature of the wastes; the speed with which they decay or decompose into simpler compounds; the amount of water into which the wastes are discharged; its assimilative capacity; and others. The technology of waste reduction, waste treatment, recycling of water, and others are part of the technologic aspect of the definition. Costs are involved at each stage and for each alternative; and values of the results are a critical aspect of each aspect. But so are goals. How much do we really value relatively pure water? How offensive do we find large scale pollution? More specifically, do we want our lakes and rivers clean enough for swimming, or are we content to purify enough water for a swimming pool? Are we prepared to undertake some costs, or to impose some controls, where the calculated benefits might not be worth the cost?

Kneese and Bower (1968) have set up models to show the interaction of these and other variables. The specific parameters, and to a lesser extent the formula itself, will depend upon the particular stream or water body. The model may be relatively simple or relatively complex; even the latter may not be fully adequate to deal with every situation which may arise. The model can be operated to show the effect of alternative assumptions or alternative programs.

\section{B. Large Scale Desalting of Sea Water for Commercial Agriculture}

The possibility of large scale desalting of sea water, to provide fresh water for large scale irrigation, in the Middle East or elsewhere, has attracted much attention in recent years. General Eisenhower (1968), relying heavily upon Admiral Strauss, has publicized the idea. Kaiser Engineers have made a report, applying specifically to Israel. (Kaiser Engineers and Catalytic Construction Co., January 1966. Engineering Feasibility and Economic Study for Dual-Purpose Electric Power-Desalting Plant for Israel.) The Oak Ridge Laboratory of the Atomic Energy Commission (July 1968) has made a more general proposal that might be undertaken in one or more of several locations, and which includes a large electro-chemical complex. A systems approach might well be used in evaluating each of these.

Any scheme for large scale irrigation from desalted sea water necessarily involves three separate but closely integrated phases: (i) a source of energy, (ii) a method of obtaining pure water from sea water, and (iii) a program for transferring water from the place and time schedules of desalting to the place and time schedule of application to the land. Although more than one method of obtaining pure water from sea water exists, most attention has focused on flash distillation processes; it may reasonably be assumed that no other process is more efficient (lower cost). Most attention has focused on nuclear power as a source of energy, but any source of energy would do. In the Middle East, 
where vastquantities of natural gas are flared and where oil at the wellhead is cheap, non-nuclear sources of energy might well be much cheaper. Nuclear power, in practical operation, has not yet turned out to be the economical source of power that 5 years ago it was expected to be. (W. E. Hoehn, 1967. The economics of nuclear reactors for power and desalting, The RAND Corp., Santa Monica, Calif., 1967; Philip Sporn, annual comments to Joint Committee on Nuclear Energy.) Nuclear power plants exhibit major economies of scale; lowest cost power is achievable only by a size of plant that produces more electricity than most countries can absorb (Landsberg, 1968). Partly as a means of utilizing a large part of this energy, the Oak Ridge proposal has included a large electrochemical complex.

The most neglected aspect of the whole process has been transference of the desalted water from place and time of desalting, to the place and time of use in the field for crop production. The desalting will take place at the margin of the sea; the land to which the water might be applied will lie inland and often athigher elevations. In Israel, for example, some of the best land to which such water may be applied is $152 \mathrm{~m}$ (500 feet) or more above sea level. Experience in the USA with irrigation clearly shows that pumping and distribution of water is far from costless. Much more serious than the place discrepancy, however, is the time discrepancy. Both the Kaiser and Oak Ridge proposals for nuclear power flash distillation of sea water provide for continuous operation, around the clock, for nearly 11 months annually-1 month or more (in one uninterrupted period) shutdown is required for servicing. You know, better than I, that farmers will not require irrigation water on this time schedule. It must be stored in surface reservoirs, in the topsoil, or in the subsoil; in each place, substantial losses will occur as well as costs incurred, and thus the cost per unit of usable water will be increased.

My earlier definition of natural resources is applicable to this idea. The relevant qualities of nature are known or can be measured: the chemical composition of sea water is known; so is the nature of nuclear reaction and the energy so released; the location and character of soils can be mapped and studied for a particular project; water consumption by cultivated crops can be estimated; and so on. The relevant technologies are fairly well known. Large scale desalting processes may encounter serious problems of sea water intake and of discharge of the hot bitter brines (Foster and Herlihy, 1965). The Oak Ridge proposal includes farm production technologies that have not yet proven feasible in comparable situations elsewhere, and much of the estimated economic feasibility of their proposal rests on such agricultural technologies.

Economics is likely to be the foundering rock for large scale desalting proposals. Atomic power is not yet "cheap"; at the best, it is competitive with fossil fuel. How might the vast amounts of energy, from a large scale nuclear plant, be utilized economically in countries with relatively small present consumption of electricity and without extensive inter-ties to other electrical systems? The costs of distillation are high; and, although the process requires a lot of energy, a large part of the cost is not for energy. Even were energy free (and "low 
cost power" can hardly get below zero), the distilled water would still be expensive. The costs of water transport and storage are likely to be high, and the value of the water for large scale commercial agriculture will be moderate if not low. The scale of the proposed projects precludes use of more than a small fraction of the water to produce flowers, out-of-season vegetables, and other specialty products. For the next 20 years, the cost of the water at the field will be one whole order of magnitude greater than its value there. (This statement draws heavily on an as-yet-unpublished article by Marion Clawson, Hans $\mathrm{H}$. Landsberg, and Lyle T. Alexander.)

But the fourth aspect of our definition--the goals or ends sought-must also be introduced here. The Oak Ridge proposal, for instance, includes a vast agro-chemical complex, a sort of enclave located within a country but not really part of it. Some proponents of this proposal have made much of this "separateness" aspect; only by setting up such an area, they argue, can the institutional, cultural, and governmental inertias that preclude modern intensive agriculture in many countries be overcome. But what lower income country wants a new, large, primarily foreign enclave, no matter how advanced technologically it may be? Many such countries had foreign plantation agriculture before the war, and few would care to introduce or re-introduce new "plantations."

The sea water desalting problem lends itself well to systems analysis. Formulae, necessarily complex and with many terms, could be devices; numerous alternatives as to size of plant, methods of operation, disposition of surplus power, transfer and storage of water, water application, cropping systems, and others could be tested, with all the feedbacks, interactions, and relationships that one could perceive. But, in this case as in all others, the results would be no better than the data and the conversion factors fed into the system analysis. Dependable results require honest and accurate components.

\section{A New Crop Variety}

At the risk of exposing my lack of knowledge, let me conclude with an example directly in your field of activity--the development and introduction of a new variety of some commercial crop. Let us assume that an agricultural research organization has developed, and tested in its research station, a new variety of some crop, which promises much higher yields. How can my definition of natural resources, and how can systems analysis, apply here?

First of all, the qualities of nature--in this case, the new variety-should be studied carefully. Just what are the genetic, nutritional, growth, flowering, seed producing, reproductive, and other characteristics of this variety? How responsive is it to, or how independent of, climatic variables such as length of day, temperatures, humidity, wind, and the like? What is its comparative performance on different kinds of soil? How responsive is it to fertilizer? How vulnerable is it to plant diseases or to insects? What special cultural practices are required for successful growth of this variety?

The technological aspects of use of this crop variety would also have to be studied. Into what natural environment would its production 
best fit? Into what kind of a farming system would it most readily be introduced and utilized? Where, and how, would its production be more marginal, and where would it be quite unsuited? What other productive inputs (fertilizer, irrigation water, etc.) would be required? By what production processes could this new variety best be grown?

The economics of use of the new variety should also be studied. Would it pay farmers to grow it, given the costs of inputs and the value of the crop? Would special incentives be needed, to persuade farmers to grow it? Would its extensive adoption increase total production so much that price would fall? If so, would it still be profitable? For some small countries, might the new variety shift the country from a net import base to a net export base, with a consequent sharp drop in price? Might there be a conflict between farmers' interests in higher prices for a modest volume, and national interest in lower prices for a much larger volume?

The goals or objectives aspects of natural resources could not be overlooked. Presumably a new variety of a familiar crop would not encounter the cultural resistances that a wholly new crop might encounter. But a new wheat might have different baking qualities, or a new rice different cooking characteristics, that might encounter some resistance. Presumably, more output would be valued more than a lesser output, all other factors equal.

All of this could be treated in a system analysis; no particularly new or novel problems seem involved. A model could be constructed, appropriate data fed into it, alternative programs tested, and so on.

\section{LITERATURE CITED}

Eisenhower, Dwight D., 1968. A proposal for our time. Reader's Digest. 92(6): 75-79.

Foster, Albert C., and Joseph P. Herlihy. 1965. Operating experience at San Diego flash distillation plant. In Proc. First Int. Symp. on Water Desalination. US Government Printing Office, Washington, D.C.

Kneese, Allen V., and Blair T. Bower. 1968. Managing water quality: Econonomics, technology, institutions. Johns Hopkins Press, Baltimore.

Land sberg, Hans H. 1968. Population growth and the potential of technology. In World population--The view ahead. Bureau of Business Research, Graduate School of Business, Indiana University, Bloomington.

Myrdal, Gunnar. 1957. Rich lands and poor. Harper \& Brothers, New York.

Oak Ridge National Laboratory. July 1968. Nuclear energy centers industrial and agro-industrial complexes--summary report. ORNL-4291, UC-80-Reactor Technology. Oak Ridge, Tenn.

Schultz, Theodore W., 1964. Transforming traditional agriculture. Yale University Press, New Haven, Conn. 